\title{
Cardiac surgery increases the activity of matrix metalloproteinases and nitric oxide synthase in human hearts
}

\author{
Irvin Mayers, MD \\ Thomas Hurst, MVSc \\ Lakshmi Puttagunta, MD \\ Anna Radomski, PhD \\ Taras Mycyk, MD \\ Grzegorz Sawicki \\ David Johnson, MD, MPH \\ Marek W. Radomski, MD, PhD
}

\footnotetext{
From the Departments of Medicine, Pathology, and Pharmacology, University of Alberta, Edmonton, Alberta, Canada, and the Departments of Medicine, Anaesthesia, and Surgery, University of Saskatchewan, Saskatoon, Saskatchewan, Canada.

Supported by a grant from the Saskatchewan Heart and Stroke Foundation.

Received for publication Oct 23, 2000; revisions requested Dec 21, 2000; revisions received March 23, 2001; accepted for publication March 26, 2001.

Address for reprints: Irvin Mayers, MD, Department of Medicine, Room 2E4.37, Walter C. Mackenzie Health Sciences Center, Edmonton, Alberta, Canada, T6G 2B7 (E-mail: imayers@ualberta.ca).

J Thorac Cardiovasc Surg 2001;122:746-52

Copyright () 2001 by The American Association for Thoracic Surgery

0022-5223/2001 \$35.00 + $0 \quad \mathbf{1 2 / 1 / 1 1 6 2 0 7}$

doi:10.1067/mtc.2001.116207
}

Objectives: Heart function is variably impaired after cardiopulmonary bypass. We hypothesized that, similar to other myocardial injury states, cardiopulmonary bypass leads to enhanced activity of nitric oxide synthase and matrix metalloproteinases.

Methods: We obtained right atrial biopsy specimens and plasma samples at the onset and termination of cardiopulmonary bypass in 10 patients. Biopsy specimens were analyzed for nitric oxide synthase activity by using a citrulline assay, whereas plasma and tissue were analyzed for matrix metalloproteinase- 9 and matrix metalloproteinase- 2 activity by using zymography. Tissue inhibitor of metalloproteinase-4 was analyzed by means of Western blotting. The cellular expression of inducible nitric oxide, endothelial nitric oxide synthase, matrix metalloproteinase2 , and matrix metalloproteinase- 9 was determined in right atrial biopsy samples from 3 additional patients by using the appropriate conjugated antibodies.

Results: Nitric oxide synthase activity increased from the beginning to the end of bypass $(4.46 \pm 1.07$ vs $16.77 \pm 4.86 \mathrm{pmol}$ citrulline $/ \mathrm{mg}$ of protein per minute, respectively; $P=.018)$. Pro-matrix metalloproteinase-9 activity increased in hearts $(199 \pm 41$ vs $660 \pm 177$ density units $/ \mathrm{mg}$ protein; $P=.008)$ and plasma $(14.1 \pm 4.6$ vs $52.2 \pm 5.9$ density units/mg protein; $P=.008$ ). Pro-matrix metalloproteinase- 2 activity increased in the heart ( $201 \pm 23$ vs $310 \pm 35$ density units/mg protein, $P<$ .05 ) but not in plasma. Tissue inhibitor of metalloproteinase-4 expression in the heart decreased (1574 \pm 280 vs $864 \pm 153$ density units, $P=.014)$.

Conclusions: Cardiopulmonary bypass activates enzymes mediating acute inflammation and organ injury (ie, nitric oxide synthase, matrix metalloproteinase-9, and matrix metalloproteinase-2). Decreased tissue inhibitor of metalloproteinase-4 expression allows relatively unopposed increases in matrix metalloproteinase tissue activity. We postulate that these changes play a role in the pathogenesis of heart dysfunction after bypass surgery.

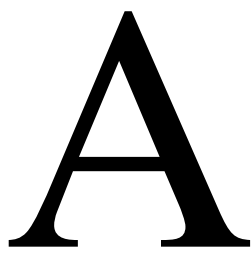

dvances in cardiopulmonary bypass (CPB) have allowed coronary artery bypass grafting (CABG) to become a common surgical procedure worldwide. ${ }^{1,2}$ Proinflammatory cytokines are released during $\mathrm{CPB},{ }^{3}$ and these cytokines are known to activate downstream signaling, leading to the generation and release of other inflammatory mediators. We have measured activities of 2 fami- 
lies of inflammatory enzymes, nitric oxide synthases (NOS) and matrix metalloproteinases (MMPs), specifically MMP9 and MMP-2. We have selected to study $\mathrm{NOS}^{4}$ and these MMPs $^{5}$ of many inflammatory mediators released during CABG because increases in their respective activities have been associated with decrements in cardiac function in human patients. We have previously shown, in a canine model, that CPB causes increased NOS activity in cardiac tissue, and this increase was associated with impaired hemodynamics. ${ }^{6}$ We have now examined changes of MMP2, MMP-9, and NOS in human cardiac tissue during CABG. To understand the biologic significance of any changes in MMP activity, we concurrently analyzed the expression of tissue inhibitor of MMP-4 (TIMP-4), an endogenous regulator of MMP activity in vivo ${ }^{7}$ and the MMP inhibitor preferentially expressed in adult heart tissue. ${ }^{5}$

\section{Materials and Methods}

The University of Saskatchewan Ethics Committee approved this study. Ten patients undergoing elective CABG (Table 1) were selected by convenience sampling. We obtained informed consent from all subjects. Intraoperative and postoperative management was not standardized but was left to the treating physicians. In general, blood cardioplegia (BCD4; Sharely, Anaheim, Calif) was commenced, initially with $30 \mathrm{mEq}$ of $\mathrm{KCl}$ and subsequently decreasing the concentration to $10 \mathrm{mEq}$ of $\mathrm{KCl}$ every 10 minutes or with evidence of electrical activity. All patients had arterial and venous blood samples drawn at the time of anesthetic induction, at the initiation of $\mathrm{CPB}$, at termination of $\mathrm{CPB}$, and 1 hour after return to the intensive care unit. Intraoperative measurements included aortic crossclamp time, total CPB time, and number of vessels grafted. Hemodynamic measurements included mean systemic blood pressure, pulmonary artery pressure, pulmonary capillary wedge pressure, and cardiac index. Blood samples were analyzed for blood gases, including oxyhemoglobin saturation, complete blood cell counts and differential, creatine phosphokinase MB fraction, and MMP activity (see below). At initiation of CPB and just before termination of CPB, strip biopsy samples (approximately $0.5 \mathrm{~cm} \times 0.5 \mathrm{~cm}$ ) of the right atrium distal to the site of cannula insertion were obtained concurrent with blood sampling. Cell-free plasma obtained by means of blood centrifugation at $2000 \mathrm{~g}$ for 5 minutes at room temperature and the biopsy specimens were snap frozen with liquid nitrogen and were stored at $-80^{\circ} \mathrm{C}$ for subsequent analysis.

MMP activity in plasma and in the homogenates of cardiac tissue was measured ex vivo by using zymography, as previously described ${ }^{8-10}$ Briefly, MMP-2 and MMP-9 were identified by their molecular weight when compared with standards, gelatinolytic activity, and the susceptibility to inhibition with MMP inhibitors. Enzyme activity was assayed by using densitometric analysis of gelatinolytic bands. ${ }^{8-10}$ The expression of cardiac TIMP-4 was measured with Western blotting. ${ }^{11}$ Samples were probed with polyclonal antibodies against TIMP-4 $(0.2 \mu \mathrm{g} / \mathrm{mL}$; Chemicon International, Temecula, Calif). Anti-mouse IgG peroxidase conjugate developed in sheep was used as a secondary antibody (Sigma,
St Louis, Mo). The detection of protein bands was carried out with an ECL detection kit (Amersham, Oakville, Ontario, Canada).

Cardiac NOS activity was measured by the rate of conversion of $\mathrm{U}^{14} \mathrm{C}$-L-arginine to $\mathrm{U}-{ }^{14} \mathrm{C}$-L-citrulline, as previously described and validated by our group. ${ }^{9}$ Briefly, samples were incubated with $\mathrm{U}-{ }^{14} \mathrm{C}$-L-arginine in assay buffer ${ }^{9}$ in the presence or absence of 1.5 $\mathrm{mmol} / \mathrm{L} \mathrm{N} \mathrm{N}^{\mathrm{G}}$-monomethyl-L-arginine to determine NOS-dependent L-citrulline formation. Etyleneglycol-bis-( $\beta$-aminoethylether)$\mathrm{N}, \mathrm{N}, \mathrm{N}^{\prime}, \mathrm{N}^{\prime}$-tetraacetic acid ( $\left.2 \mathrm{mmol} / \mathrm{L}\right)$, a calcium-chelating agent, was used to differentiate between $\mathrm{Ca}^{2+}$-dependent and $\mathrm{Ca}^{2+}$-independent activity. ${ }^{9}$ After 20 minutes of incubation, the reaction was terminated by means of dilution and removal of nonreacted L-arginine with AG50W-X8 resin (Bio-Rad), and the remaining radioactivity was counted and taken for calculation of NOS activity.

These biopsy samples were too small to allow us to obtain concurrent evaluation with immunohistochemistry. Therefore after the initial 10 patients completed this protocol, we obtained strip biopsy samples from a further 5 patients at time points identical to those described above. These samples were immediately placed in buffered formalin and then embedded in paraffin. We obtained 4to $5-\mu \mathrm{m}$ sections from the paraffin blocks of the formalin-fixed cardiac tissue biopsy specimens. We obtained hematoxylin and eosin-stained sections and performed immunoperoxidase tests on the basis of the streptavidin-biotin method. Briefly, samples were prepared by mounting $4-\mu \mathrm{m}$ thick slices of formalin-fixed paraffinembedded heart sections onto Aptex-coated slides and then drying them overnight at $37^{\circ} \mathrm{C}$. Staining of the slides was completed after 10 minutes of heating at $70^{\circ} \mathrm{C}$, deparaffinization with xylene, and rehydration with decreasing grades of ethanol ending with water. Slides were next soaked in $\mathrm{H}_{2} \mathrm{O}_{2}$ /methanol solution for 6 minutes and later rinsed with water to block endogenous peroxidase. Antigen retrieval was accomplished by microwaving slides in citrate buffer. Counterstaining was done with Harris' Haematoxylin. Blocking reagent (20\% normal goat serum) was applied to each slide, followed by 15 minutes of incubation at room temperature. Primary antisera consisted of mouse anti-human monoclonal antibodies for endothelial NOS (eNOS) and inducible NOS (iNOS; 5 $\mu \mathrm{g} / \mathrm{mL}$; Transduction Laboratories, Lexington, Ky), as well as polyclonal anti-peptide antibodies $(1 \mu \mathrm{g} / \mathrm{mL})$ against MMP-2 ${ }^{12}$ and MMP-9. ${ }^{13}$ Normal serum was used for negative controls. After 30 minutes of incubation with primary antibody, slides were rinsed with phosphate-buffered saline (PBS) for 5 minutes and then incubated for an additional 20 minutes with the link reagent (biotinylated anti-mouse or anti-rabbit $\mathrm{IgG}, 2-10 \mu \mathrm{g} / \mathrm{mL}$; VectorLab, Burlingame, Calif). After 1 minute of PBS rinse, the streptavidin peroxidase label reagent (Biogenex, San Ramou, Calif) was applied for 20 minutes at room temperature. Next, a final PBS rinse was followed by 5 minutes of incubation with the chromagen solution 3,3'-diaminobenzidine plus $\mathrm{H}_{2} \mathrm{O}_{2}$. Finally, the slides were dehydrated, cleared, and mounted for viewing. All slides were reviewed by a pathologist (L.P.) at $40 \times$ to $400 \times$ magnification.

We analyzed changes in variables from the initiation of bypass to the termination of bypass with the Wilcoxon matched-pairs signed-rank test. Relationships between variables were determined with Spearman correlation. We decided to use nonparametric statistics because of the small sample size and the chance that one or more of the contrast variables did not meet the assumptions of normality. All values are expressed as means \pm SE. 

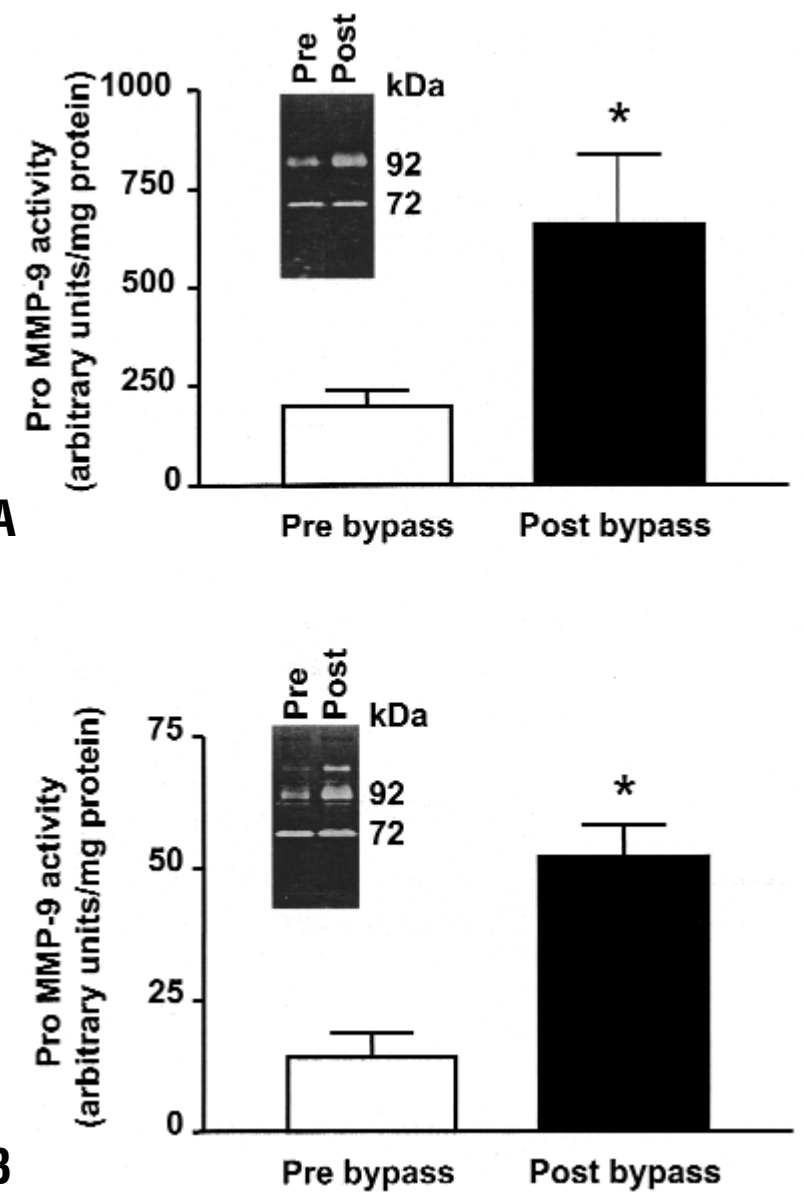

Figure 1. Pro-MMP-9 activity in right atrium (A) and in plasma (B) is increased after bypass. Data are presented as means $\pm \mathrm{SE}$. *Significant difference $(P<.05)$ between the paired samples. Insert is a representative patient sample analyzed by means of zymography. Note that the activity of the 72-kd enzyme is indicative of pro-MMP-2, and that of the 92-kd activity is indicative of pro-MMP-9.

\section{Results}

We analyzed the initial 10 subjects for whom enzyme activities were measured separately from the subsequent 5 patients for whom tissue immunohistochemistry analysis was performed. Our initial 10 patients were $66 \pm 3.2$ years of age (range, 51-80 years). None of the patients experienced serious complications from the operation. All recovered uneventfully and were discharged home. Their length of stay in the hospital was $6.7 \pm 0.8$ days (range, 5 -14 days). The mean time on CPB was $110 \pm 5.4$ minutes, with an aortic crossclamp time of $80 \pm 5.1$ minutes. Table 1 summarizes the measurements of routine clinical and hematologic parameters. Of note, there was an increase in white blood cell counts (WBCs) after cardiac surgery. The decrease in hemoglobin levels represents the routine clinical hemodilution

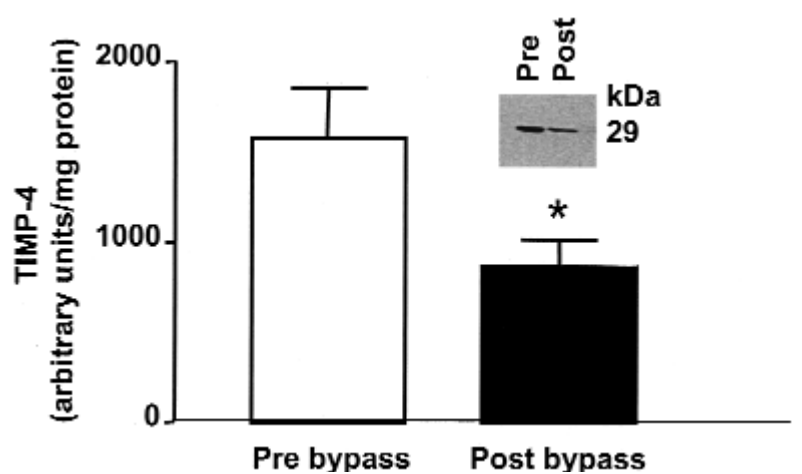

Figure 2. Decrease in TIMP-4 expression in right atrium after bypass. Data are presented as means $\pm \mathrm{SE}$. *Significant difference $(P<.05)$ between the paired samples. Insert is a representative patient sample analyzed by means of Western blotting. The activity at $29 \mathrm{kd}$ is indicative of TIMP-4.

TABLE 1. Routine clinical and hematologic parameters

\begin{tabular}{lcc}
\hline & Preoperative & Postoperative \\
\hline Cardiac index $\left(\mathrm{L} \cdot \mathrm{min}^{-1} \cdot \mathrm{m}^{-2}\right)$ & $2.1 \pm 0.2$ & $2.2 \pm 0.2$ \\
MAP $(\mathrm{mm} \mathrm{Hg})$ & $86 \pm 4.4$ & $93 \pm 4.1$ \\
Ppa $(\mathrm{mm} \mathrm{Hg})$ & $23 \pm 1.9$ & $17 \pm 1.3^{*}$ \\
Pcwp & $14 \pm 1.3$ & $11 \pm 1.3^{*}$ \\
SVR (dynes $\left.\cdot \mathrm{s}^{-1} \cdot \mathrm{cm}^{-5}\right)$ & $2798 \pm 151$ & $3069 \pm 302$ \\
Hemoglobin $(\mathrm{mg} / \mathrm{dL})$ & $111 \pm 4.4$ & $85 \pm 5.1^{*}$ \\
WCB $\left(10^{9} \mathrm{cells} / \mathrm{L}\right)$ & $5.4 \pm 0.5$ & $9.0 \pm 1.1^{*}$ \\
CK-MB $(\% \mathrm{CK})$ & $2.6 \pm 1.7$ & $3.6 \pm 1.4$ \\
\hline
\end{tabular}

All data are presented as means \pm SEM. MAP, Mean arterial blood pressure; $P p a$, pulmonary artery pressure; $P c w p$, pulmonary capillary wedge pressure; $S V R$, systemic vascular resistance; $C K-M B$, creatine phosphokinase MB fraction.

*Significant difference from initiation to termination of CPB $(P<.05)$, as determined with the Wilcoxon signed-rank test.

found after CPB. Other noted hemodynamic changes were not of clinical significance.

The zymographic activity of pro-MMP-9 increased (Figure 1) from initiation of bypass to termination of bypass in cardiac tissue (Figure 1, $A ; P=.008$ ) and plasma (Figure $1, B ; P=.008)$. The zymographic activity of pro-MMP-2 was increased in cardiac tissue $(201 \pm 23$ vs $310 \pm 35$ density units $/ \mathrm{mg}$ protein, $P<.001$ ), but the increase in plasma zymographic activity could have been caused by chance alone $(P>.2)$. The expression of TIMP-4 decreased $(P=$ $.036)$ over the time period (Figure 2). The cardiac biopsy specimens stained with hematoxylin and eosin did not demonstrate important changes from initiation to termination of CPB. Detailed examination of the cardiac biopsy specimens showed one specimen (a post-CPB sample) with 


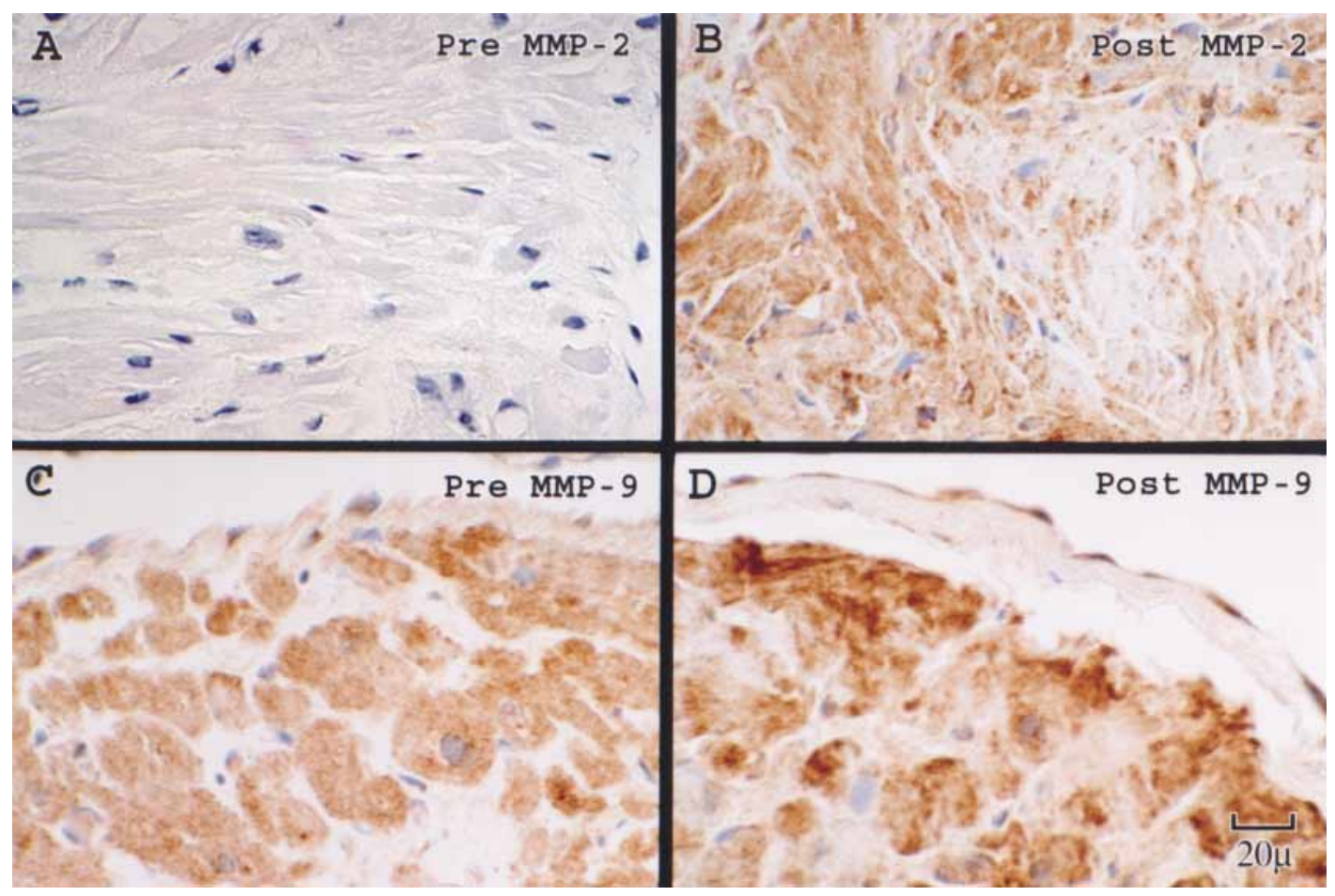

Figure 3. Distribution of MMP expression in the right atrium. Staining for MMP-2 expression increases from onset (A) and at termination (B) of CPB in a representative tissue sample. Similarly, staining for MMP-9 expression increases at onset (C) and at termination (D) of CPB. Note that the tissue sections have been magnified at $160 \times$.

a rare cluster of neutrophils within the myocardium within an area of hemorrhage. All of the other biopsy specimens show patchy interstitial fibrosis with little inflammatory cell infiltrate. Using immunohistochemistry, we found that MMP-2 and MMP-9 were expressed diffusely in cardiac myocyte cytoplasm throughout the sample. The intensity of staining clearly increased in myocytes from initiation to termination of CPB. Figure 3 illustrates the typical findings observed in all the tissue sections visually inspected.

Total cardiac NOS activity before bypass was $4.46 \pm 1.07$ pmol citrulline/mg protein per minute; $\mathrm{Ca}^{2+}$-dependent NOS activity accounted for $75 \%$ of total activity, and the remaining activity was $\mathrm{Ca}^{2+}$ independent. Total NOS activity was increased $(P=.018)$ up to $16.77 \pm 4.86 \mathrm{pmol} \cdot \mathrm{mg}^{-1}$ - $\mathrm{min}^{-1}$ from initiation to termination of bypass (Figure 4 ). However, the ratio between $\mathrm{Ca}^{2+}$-dependent and $\mathrm{Ca}^{2+}$-independent enzymes remained similar. We also evaluated the distribution of cardiac NOS expression by means of immunohistochemistry (Figure 5). In keeping with the changes in enzyme activity, there was also a slight but clearly distinguishable increase in tissue staining for both iNOS and eNOS from initiation to termination of CPB.

There was a positive correlation between the activity of tissue pro-MMP-9 and the tissue activity of NOS $(P=$

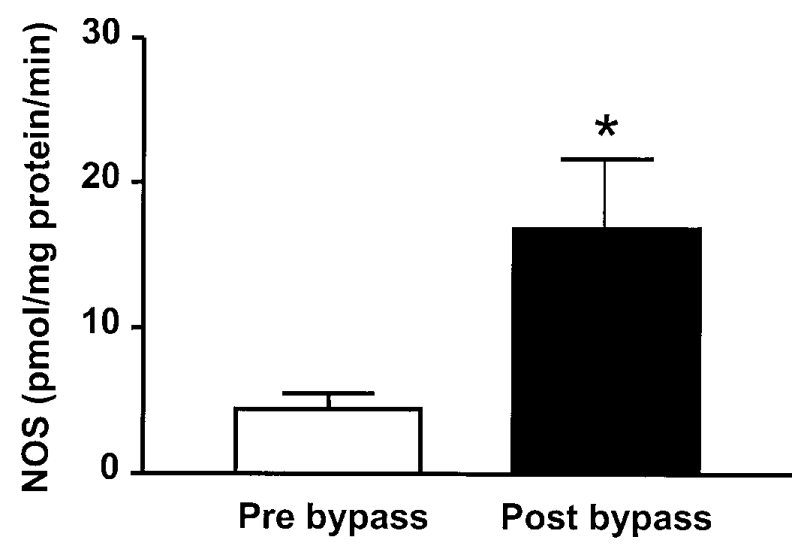

Figure 4. Increased NOS activity in the right atrium. Data are presented as means $\pm S E$. *Significant difference $(P<.05)$ between the paired samples.

$.0234, \rho=0.82$ ). We also examined correlations between the measured enzyme activities and observed clinical parameters. We found that tissue activity of pro-MMP-9 increased with increasing duration of $\mathrm{CPB}$ time $(P=.0092, \rho=0.77)$. We also found that WBCs increased with increasing plasma pro-MMP-9 activity $(P=.0412, \rho=0.69)$. Similarly, neu- 


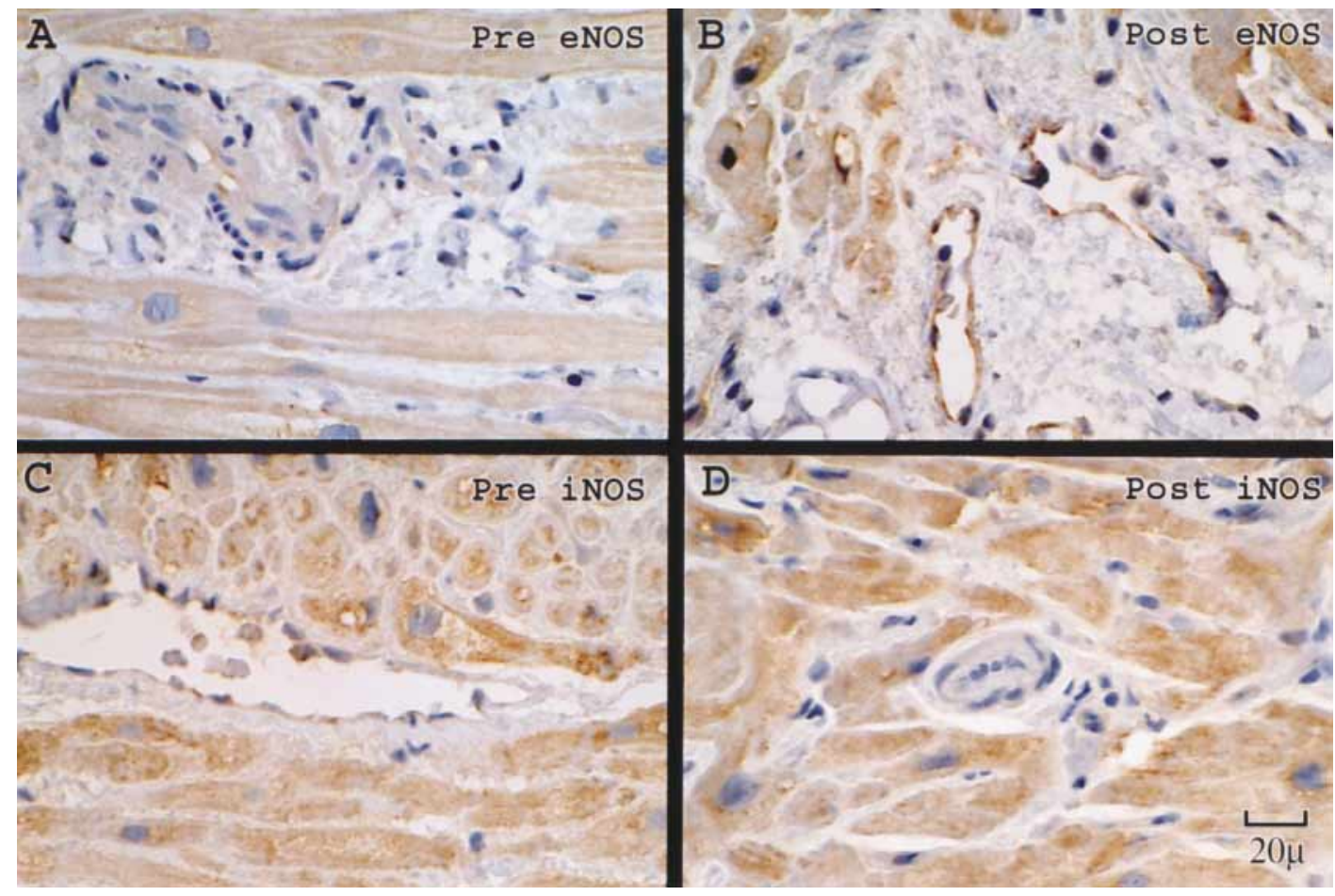

Figure 5. Distribution of NOS activity in the right atrium. There is a slight increase in staining for eNOS expression from onset $(A)$ to termination (B) of CPB. There is a similar slight increase of staining for iNOS expression from onset (C) to termination (D) of CPB. Note that the tissue sections have been magnified at $160 \times$.

trophil counts increased with decreasing cardiac TIMP-4 activity $(P=.048, \rho=0.69)$.

\section{Discussion}

Myocardial function is transiently impaired after coronary bypass surgery, and this impairment is often ascribed to the procedure of $\mathrm{CPB} .{ }^{14}$ The procedure of $\mathrm{CPB}$ includes multiple components, including, but not limited to, the extracorporeal circulation, ischemia, reperfusion, and autotransfusion of shed blood. This procedure increases release of proinflammatory cytokines. ${ }^{10,11,15,16}$ Proinflammatory cytokines (eg, tumor necrosis factor $\alpha$, interleukin $1 \beta$, and interleukin 6), in turn, are known to induce the generation of mediators of inflammation. Nitric oxide is one major inflammatory mediator induced by these cytokines, and its overproduction has been associated with impaired cardiac muscle performance. ${ }^{4,17}$ Myocardial NO levels and NOS activity are increased after CPB in experimental animals, ${ }^{18}$ and we now confirm that myocardial NOS activity is also increased in human patients undergoing coronary artery bypass surgery.

At initiation of $\mathrm{CPB}$, we found the presence of $\mathrm{Ca}^{2+}$ independent iNOS in addition to the expected finding of $\mathrm{Ca}^{2+}$-dependent eNOS in these human myocardial samples. We also found that both myocardial $\mathrm{Ca}^{2+}$-dependent NOS and $\mathrm{Ca}^{2+}$-independent NOS activities are increased during the procedure of coronary artery bypass surgery. Our immunohistochemical examination indicates that the increased expression of eNOS and iNOS in myocytes could account for the increased enzyme activities, and we do not need to invoke the presence of inflammatory cell infiltration as the source of these enzymes. If, as has been shown in animal studies, increased expression of myocyte NOS alters the contractile properties of the myocardium, ${ }^{17}$ then our current observations may account for some of the decreased contractility seen after human CABG. Although in this study we cannot ascribe which part of CABG surgery causes these increases of NOS activity (ie, grafting versus $\mathrm{CPB}$ ), our previous canine studies ${ }^{6}$ would suggest that the process of CPB is most responsible.

MMP enzymes, such as MMP-2 and MMP-9, are also induced by proinflammatory cytokines. ${ }^{19}$ Therefore we had postulated that the activity of these MMPs should also increase during CPB. Before CABG surgery, we found that myocardium demonstrated measurable activities of both MMP-2 and MMP-9. However, the tissue sections examined by means of immunohistochemistry could only demonstrate the presence of MMP-9 and did not reveal any MMP-2 immunoreactivity. The discrepancy between enzyme activity assay (zymography) and immmunohistologic technique 
is best explained by a differential sensitivity of these assays (ie, the enzyme assay is the more sensitive test). As with any assay performed in vitro, zymography may not accurately reflect the enzyme net activity in vivo. However, this assay has been validated in numerous other conditions. We have not only shown increased enzyme zymographic activity but also demonstrated increased enzyme protein expression by using immunohistochemistry. This increase in MMP activity is of biologic significance because we have concurrently shown that the expression of the major myocardial inhibitor of metalloproteinases, TIMP-4, is depressed after cardiac surgery. Thus the zymographic activity of the MMPs is increased, and at the same time, the activity of the inhibitor of MMPs is decreased, resulting in relatively unopposed MMP activity immediately after coronary artery bypass surgery. There is as yet no direct correlation of changes in MMP cardiac tissue activity with specific clinical outcomes after human cardiac surgery. However, there is evidence linking increased MMP activity with cardiac dysfunction in other settings. Both human and animal studies have shown that cardiac MMP-9 activity is increased ${ }^{7,20}$ and cardiac TIMP-4 concentration is decreased ${ }^{7}$ in the setting of chronic cardiomyopathy. Cardiac MMP-9 and MMP-2 activity are acutely increased in rat and porcine models of ischemiareperfusion. ${ }^{10,21}$ Moreover, selective inhibition of MMP-2 decreased cardiac dysfunction caused by an ischemia-reperfusion injury. ${ }^{10}$ More recently, a synthetic inhibitor of MMP activity has been shown to prevent acute lung injury in a porcine model of lung injury induced by the combination of CPB with endotoxin. ${ }^{22}$ Together, these studies suggest that MMP-2 and MMP-9 are important effector enzymes involved in the structural remodeling of the heart after treatment-induced or disease-induced inflammatory reactions. There are data from a wide variety of sources that other MMPs may also play a role in the development of cardiac dysfunction in other settings (eg, congestive heart failure). However, because we focused our study on changes in MMP-2, MMP-9, and TIMP-4, we cannot state whether similar changes occur in other MMPs or TIMPs.

We were able to show that the increased MMP zymographic activity in the heart was not caused by the influx of inflammatory cells. There was not histologic evidence of inflammatory cell infiltration in the cardiac biopsy specimens, with the exception of one slide showing neutrophils, but only in the presence of hemorrhage. Instead, there is a diffuse increase in MMP expression within myocytes, as demonstrated immunohistochemically. The intramyocyte localization of MMPs after CPB may have pathologic significance. In patients with dilated cardiomyopathy, both MMP-2 and MMP-9 are associated with sarcomeres, and these MMPs ${ }^{23}$ were shown to digest the proteins that built up the contractile apparatus of the myocyte. There is now also evidence that overexpression of MMP-1 can also lead to cardiac dysfunction through breakdown of the cardiac extracellular matrix. ${ }^{24}$ Thus overactivity of MMPs in other settings has been shown to disrupt normal myocyte structures and lead to cardiac dysfunction.

The adverse effects of $\mathrm{CPB}$ are not just restricted to the heart but are systemic in nature. In effect, CPB can be considered as a form of inflammatory injury, ${ }^{3}$ the precise onset of which is controlled (ie, the initiation of extracorporeal flow). There is an almost universal decrement in pulmonary function after CPB. ${ }^{25}$ In addition, there is frequently a diffuse brain injury after $\mathrm{CPB}$, with $3 \%$ of patients undergoing cardiac surgery demonstrating significant intellectual deterioration postoperatively, even in the absence of an overt structural brain injury. ${ }^{26} \mathrm{We}$ found that plasma pro-MMP-9 zymographic activity was immediately increased after CPB. This supports our contention that the enzyme changes found in the myocardium are markers of a more diffuse systemic inflammatory process, but it is also possible that the heart was the primary systemic source of this increased enzyme activity. As pump time increased, so too did pro-MMP-9 zymographic activity, thus suggesting that this enzyme is indeed associated with a more intense systemic insult. Moreover, MMP-2 zymographic activity is elevated during extracorporeal membrane oxygenation, and this release correlates with platelet activation and injury. ${ }^{11}$ Thus MMPs may also exert systemic effects in patients after various forms of extracorporeal circulation.

We detected a complex interrelationship among MMP-9, TIMP-4, and WBCs. Because cardiac surgery resulted in increased WBCs, this correlated with an enhancement of MMP-9 and reduction of TIMP-4 levels. Because no infiltration of inflammatory cells could be detected in the myocardium, the relationship between $\mathrm{WBC}$ and the MMP-TIMP system could reflect the presence of systemic inflammatory response initiated by cardiac surgery, of which MMPs are an integral part.

The clinical significance of these findings is not yet known. Our population sample is too small to make a meaningful correlation with specific clinical outcomes (ie, mortality, length of hospital stay, and organ function). We did not recruit the requisite sample size to make these clinical correlations because we did not know, a priori, that there would be any measurable enzyme changes. However, there are other studies suggesting that increased cardiac NOS activity or increased cardiac MMPs zymographic activity may be detrimental to heart function. ${ }^{4,5,17,27}$

In summary, we have found direct evidence of increased activity of NOS, MMP-2, and MMP-9 after human cardiac surgery. The clinical importance of these findings is uncertain, but these findings may point to new treatments to improve clinical outcomes of cardiac surgery. 


\section{References}

1. Rothlisberger C, Meier B. Coronary interventions in Europe. The Working Group on Coronary Circulation of the European Society of Cardiology. Eur Heart J. 1992;16:922-929.

2. Naylor CD, Ugnat AM, Weinkauf D, Anderson GM, Wielgosz A. Coronary artery bypass grafting in Canada: what is its rate of use? Which rate is right? CMAJ. 1992;146:851-9.

3. Downing SW, Edmunds LH Jr. Release of vasoactive substances during cardiopulmonary bypass. Ann Thorac Surg. 1992;54:1236-43.

4. Haywood GA, Tsao PS, von der Leyen HE, Mann MJ, Keeling PJ, Trindade PT, et al. Expression of inducible nitric oxide synthase in human heart failure. Circulation. 1996;93:1087-94.

5. Greene J, Wang M, Liu YE, Raymond LA, Rosen C, Shi YE. Molecular cloning and characterization of human tissue inhibitor of metalloproteinase 4. J Biol Chem. 1996;271:30375-80.

6. Mayers I, Salas E, Hurst T, Johnson D, Radomski MW. Increased nitric oxide synthase activity following canine cardiopulmonary bypass is suppressed by S-nitroso-glutathione. J Thorac Cardiovasc Surg. 1999;117:1009-16.

7. Li YY, Feldman AM, Sun Y, McTiernan CF. Differential expression of tissue inhibitors of metalloproteinases in the failing human heart. Circulation. 1998;98:1728-34.

8. Sawicki G, Salas E, Murat J, Miszta-Lane H, Radomski MW. Release of gelatinase A during platelet activation mediates aggregation. Nature. 1997;386:616-8.

9. Radomski A, Sawicki G, Olson DM, Radomski MW. The role of nitric oxide and metalloproteinases in the pathogenesis of hyperoxiainduced lung injury in newborn rats. Br J Pharmacol. 1998;125:145562.

10. Cheung P-Y, Sawicki G, Wozniak M, Wang W, Radomski MW, Schulz R. Matrix metalloproteinase- 2 contributes to the ischemia-reperfusion injury in the heart. Circulation. 2000;101:18339.

11. Cheung P-Y, Sawicki G, Salas E, Etches PC, Schulz R, Radomski MW. The mechanisms of platelet dysfunction during extracorporeal membrane oxygenation in acutely ill neonates. Crit Care Med. 2000;28:2584-90.

12. Fernandez-Patron C, Martinez-Cuesta MA, Salas E, Sawicki G, Wozniak M, Radomski MW, et al. Differential regulation of platelet aggregation by matrix metalloproteinase- 9 and -2 . Thromb Haemost. 1999;82:1730-5.

13. Sawicki G, Radomski MW, Lowen B, Krzymien A, Guilbert LJ. Polarized release of matrix metalloproteinase (MMP) -2 and -9 from cultured human placental syncytiotrophoblasts. Biol Reprod. 2000;63:1390-5.

14. Breisblatt WM, Stein KL, Wolf CJ, Follansbee WP, Capozzi J, Armitage JM, et al. Acute myocardial dysfunction and recovery: a common occurrence after coronary bypass surgery. J Am Coll Cardiol. 1990;15:1261-9.

15. Brasil LA, Gomes WJ, Salomao R, Buffolo E. Inflammatory response after myocardial revascularization with or without cardiopulmonary bypass. Ann Thorac Surg. 1998;66:56-9.

16. Finkel MS, Hoffman RA, Shen L, Oddis CV, Simmons RL, Hattler BG. Interleukin-6 (IL-6) as a mediator of stunned myocardium. Am J Cardiol. 1993;71:1231-2.

17. Finkel MS, Oddis CV, Jacob TD, Watkins SC, Hattler BG, Simmons RL. Negative inotropic effects of cytokines on the heart mediated by nitric oxide. Science. 1992;257:387-9.

18. Morita K, Ihnken K, Buckberg GD, Sherman MP, Young HH, Ignarro LJ. Role of controlled cardiac reoxygenation in reducing nitric oxide production and cardiac oxidant damage in cyanotic infantile hearts. $J$ Clin Invest. 1994;93:2658-66.

19. Yao PM, Maitre B, Delacourt C, Buhler JM, Harf A, Lafuma C. Divergent regulation of $92-\mathrm{kDa}$ gelatinase and TIMP-1 by HBECs in response to IL-1beta and TNF-alpha. Am J Physiol. 1997;273:L86674.

20. Gilbert SJ, Wotton PR, Tarlton JF, Duance VC, Bailey AJ. Increased expression of promatrix metalloproteinase-9 and neutrophil elastase in canine dilated cardiomyopathy. Cardiovasc Res. 1997;34:377-83.

21. Danielsen CC, Wiggers H, Andersen HR. Increased amounts of collagenase and gelatinase in porcine myocardium following ischemia and reperfusion. J Mol Cell Cardiol. 1998;30:1431-42.

22. Carney DE, Lutz CJ, Picone AL, Gatto LA, Ramamurthy NS, Golub LM, et al. Matrix metalloproteinase inhibitor prevents acute lung injury after cardiopulmonary bypass. Circulation. 1999;100:400-6.

23. Rouet-Benzineb P, Buhler JM, Dreyfus P, Delcourt A, Dorent R, Perennec J, et al. Altered balance between matrix gelatinases (MMP2 and MMP-9) and their tissue inhibitors in human dilated cardiomyopathy: potential role of MMP-9 in myosin-heavy chain degradation. Eur J Heart Fail. 1999;1:337-52.

24. Kim HE, Dalal SS, Young E, Legato MJ, Weisfeldt ML, D'Armiento J. Disruption of the myocardial extracellular matrix leads to cardiac dysfunction. J Clin Invest. 2000;106:85766.

25. Singh NP, Vargas FS, Cukier A, Terra-Filho M, Teixeira LR, Light RW. Arterial blood gases after coronary artery bypass surgery. Chest. 1992;102:1337-41.

26. Roach GW, Kanchuger M, Mangano CM, Newman M, Nussmeier N, Wolfman R, et al. Adverse cerebral outcomes after coronary bypass surgery. N Engl J Med. 1996;335:1857-63.

27. Thomas CV, Coker ML, Zellner JL, Handy JR, Crumbley AJ 3rd, Spinale FG. Increased matrix metalloproteinase activity and selective upregulation in LV myocardium from patients with end-stage dilated cardiomyopathy. Circulation. 1998;97:1708-15 